to the amount supplied is a practical way to control the amount consumed.

I have nony apologies to make for this paper, but while knowing that I have not offered any new or brilliant ideas, I trust that my simple effort to sugrasest what is practical may be productive of help to some.

\title{
THE AFFILIATION OF TRAINING-SCHOOLS
}

\author{
BY MISS M. HELENA MCMILLAN
}

Principal of Training-School, Presbyterian Hospital, Chicago, Ill.

Frour East, West, North and South reports come of what has been accomplished in the way of affiliation, what is being done, and what is planned for the future. Affiliation is not a new thing, although in its broadest, best form we as yet hardly know it, and possibly are not ready for it.

Temporary union through the courtesy of one superintendent and one school to assist another has occurred from time to time as occasion arose. As many as a dozen years ago a Cincinnati hospital, having decided to give up its work, was able to properly provide for the completion of the training of its pupils by the willingness of neighboring schools to receire its nurses as their own; the Illinois Training-School of Chicago and another Western school, whose name I have been unable to find, aiding in this by accepting the members of the senior class. for their final months. In a similarly courteous manner, some years later, the Allegheny General Hospital, Pittsburg, to assist the Pittsburg General for Children, undertook the entire charge of the nursing in that hospital for three years while a new building was being put up, and in turn the Pennsylrania Hospital of Philadelphia came to the assistance of the Allegheny General by receiving its senior class until affairs adjusted themselves in the first two institutions.

Nurses' schools, particularly those connected with the large city hospitals, have, for an indefinite time, been working together, supplementing in a second or third institution the experience in practical nursing deemed necessary for a complete training and which the first was unable to provide. General hospitals have gladly sent their nurses to special institutions, such as maternities, children's or contagious hospitals and eye and ear infirmaries, thus accomplishing the threefold 
object of broadening their own training, providing suitable care for the sick of the institution, and preventing necessity for the existence in these special hospitals of poorly-equipped and inadequate schools.

New York, Boston, C'hicago and other cities abound in instances of this type of affiliation, so well known to us all that it is needless to cite examples. Not a few schools have been sufficiently interested in securing the complete training for their nurses to send them, sometimes at considerable cost to the school, to other cities or states; as the Leonard Morse, Natick, Mass., to Lying-In Hospital, Providence, R. I.; Lakeside Hospital, Cleveland, Ohio, to New York Lying-In Hospital; Riverside Hospital, Toronto, Canada, to the Woman's and to the Infants' Home, Detroit; Butterworth Hospital, Grand Rapids, Michigan, to Detroit; Home and Retreat, Lynchburg, Va., to the Presbyterian, Chicago; and others.

Possibly of more recent date and particularly noticeable within the last year or two, is that form in which the large general hospital, opening its doors, admits other school nurses into its wards and class-rooms, thus assisting the school belonging to a hospital with limited or special service. Among these we find Buffalo General receiving nurses from the Children's Hospital of Buffalo for their third year; Johns Hopkins opening its obstetrical department to the pupils of the Union Protestant Infirmary of Baltimore; and, possibly, giving before long the same opportunity to the school of the Church Home and Infirmary. To the latter, in addition, will be granted the privilege of having their nurses attend the intermediate and senior class lectures of the Johns Hopkins which are not provided for in their own school; The Illinois TrainingSchool is now adnitting into the Cook County Hospital nurses of the Browak and Dixon Hospitals of Illinois and the Passavant of Chicago. Maryland General, Baltimore, trains the St. Agnes Training-School nurses in obstetrics; New York Post-Graduate is open, during the summer months, to the school of the Jackson Health Resort, Danville, N. Y.; Policlinic of Philadelphia receives nurses of the Woman's Hospital of that city into its male wards and accident rooms; and $M t$. Sinai of New York is open to schools connected with insane institutions, giving to the nurses four months' training, part of which time is in the operating-room.

Several schools of the specialty hospitals are fully awake to these opportunities and are making the most of them. The Jackson Health Resort, besides sending its nurses to the Post-Graduate of New York, is affiliated with the Erie County Hospital and with Dr. Mann's Gynæ- 
cological Hospital, Buffalo; with the New York Infirmary for Women and Clildren; with the Laura Franklin Free Hospital for Children, New York, and with the Nursery and Children's Hospital. Another following the same plan is the Laura Franklin Frce Hospital for Children, New York, in which the nurse spends the first year in her own hospital, and is prepared as well as possible in the theory and practice of nursing in all branches; the second year she is sent for adult training to the J. Hood Wright Memorial Hospital, where in addition to surgical, medical and gynrcological nursing she has experience in dispensary work; to the New York Infant Asylum; to the Minturn for Contagious; and for instruction in district nursing she is placed under the superrision of the staff of the Nurses' Settlement.

The Sheppard and Enoch Pratt Hospital for Nervous and Mental Diseases has been able to make an arrangement with the Post-Graduate of New York by which women who wish training in general nursing after the two years course in special instruction in this hospital, may "under certain restrictions be admitted as advanced pupils in the New York Post-Graduate Hospital and Training-School and be allowed one year's credit there."

A somewhat different affiliation of two hospitals to provide educational material for one school is instanced in the Capital City School of Nursing, Washington, D. C. Both institutions,-namely, the Washington Asylum Hospital and the Central Dispensary and Emergency Hospital, has nurses' homes, class and lecture-rooms. Applications are accepted by the Superintendent of Nurses of the Washington Asylum Hospital, where the first two years are spent. The final year the nurse goes to the Central Dispensary and Emergency Hospital. As I understand it, the entire course of instruction, theoretical as well as practical, is planned together by the two women representing these hospitals, and not by the head of one only who arranges and possibly dictates terms to the second, an example well worthy of note and of emulation.

A form of affiliation less common is that of nurses' school with college, instanced in the Presbyterian Hospital of Chicago, where upon the organization of the school in 1903, Rush Medical College offered to assume responsibility for the instruction of the pupils in those subjects ordinarily taught in a medical school and the use of its laboratories and class-rooms. This offer was gladly accepted by the school and has been found most helpful, results having been thus obtained which otherwise would have been impossible.

During the past year the Provident (for colored women) and Wesley Hospitals of Chicago, and to a lesscr degree the Mercy Hospital, have 
united in class, lecture and laboratory work, this being given by the staff and in the class-rooms of the Northwestern University. The three named hospitals as yet have not affiliated in practical nursing instruction, but I understand there are plans along this line and some hope for a nuch closer union during the coming year.

An affiliation somewhat similar to the above was in existence several years ago in two or more hospitals in Rochester, New York, but does not now exist. City Hospital, St. Barnabas, and others of Minneapolis, Minn., unite to receive some of their lectures together, and they have hopes that the University of Minnesota will, before long, assist them in establishing preliminary instruction, and in such other work as the university is prepared to be helpful in.

State rcgistration has aided somewhat in this tendency towards united effort, one direct result of the passage of a nursing bill being. the abandonment of the school connected with the Crippled Children's Hospital, Baltimore, and the assumption of the nursing in that institution by the University of Maryland Training-School.

Also as the result of registration is the offer recently made by the school of the City Hospital of Indianapolis to receive nurses of other schools in their second year, giving them work in the wards of the hospital, lectures, classes and demonstrations. Massage and dietetics are added, but each aftiliated school must bear the expense of instruction in those two subjects.

Ordinarily the hospital receiving the nurse provides board, lodging and laundry. Occasionally she returns to her own home at night. In a few cases a small montlly remittance is paid to the home school or directly to the nurse. Also at times the nurse visiting is provided with and expected to wear the hospital uniform while a resident. In every instance heard from the transportation expenses are paid by the sending school.

In discussing affiliation superintendents who have had experience write as follows: One says, "It is good for young nurses to come in contact with nurses from other schools, with other methods of work, and to have the opportunity of seeing other physicians than those of their own community." A second claims that there are certain disadvantages: "Nurses become relaxed in discipline, not bein $n_{\xi}$ under the supervision of those who know them, are inclined to adopt methods which they consider easier and which are always less effectual, and consequently they return very often so confused with different methods as to have neither one way nor another. They also lose their class time and lectures." Another: "We have found affiliation satisfactory in 
all respects." A fourth: "It makes nurses broader minded, more adaptable and tactful," while still one more says that the bencfit received is not entirely on the side of the small hospital, and hopes that the women at the head of the large schools will become morc generous in opening their doors to others.

Even such an incomplete sketch as has becn offered shows that a great deal has been accomplished and is being planncd for. Most of the states in which aftiliation is not alrcady known (and there are several both East and West). express the need and wish for it. However, affiliation as it is is not what we mould have it nor what we hope it may be. There are undoubtedly many difficulties in the way of closer and broader union. Some general hospitals, which would gladly be of use to others, are unable to give those services mostly in demand,-namely, children, obstetrical and contagious,-needing what they may have for their own pupils. It rould seem possible, however, to follow the example set of lending some of their medical, surgical and other adult material to those who need it, without in any way lessening the excellence of training in their own schools. The use of the special hospitals, when within reach, seems to be pretty generally appreciated, but the supply of these will hardly meet the demand.

The tendency noticeable towards affiliation in class and lecture is pleasing and worthy of encouragement. In this way the cost of instructors might be divided, making the use of the salaried teacher much more possible and common.

May it not seem plausible to suggest that those two or three Western schools which hare joined with themselves and again with an educational center have started on the road to the solution of the problem which in time will lead to the dcsired good? By their own union they bring combined knowledge and experience in working out a suitable course of instruction, and provide the necessary nurse instructors; through their relationship with the several hospitals they obtain the desired clinical material; and by their affiliation with a university, already equipped with laboratories and their expensive requirements, thcy have the privilege of their use and the advantage of instructors and lecturers specially trained in those subjects which, at present at least, nurse instructors are not prepared to teach most effectively.

If nurses' schools are ever to become distinctively educational, they must associate themselves with other educational organizations, must become part of an educational organism. At present they are parts of a whole, but the whole has aspirations which satisfy only one side of the part. Hospitals exist to provide for the care of the sick; they may 
lend themselves, to a certain extent, to educational purposes, but never can or should be educational centers, or assume to a large degree educational problems. The school (part of the hospital) exists to nurse the sick but also to fulfill a duty equally as important to the community,that is, to educate its student nurses, - and accordingly must undertake and solve these educational problems. It might seem, therefore, that the part is broader than the whole, a condition which ties the hands of the schools for nurses and makes their progress, beyond a limited degree, impossible.

Should we throw aside the hospitals, which is out of the question, and if possible, undesirable, and endeavor to unite ourselves to the universities alone, we might say, with equal truth, that the whole would fail to satisfy all needs of the part. Nurses' schools are distinctively twofold: giving care to the sick, and for this they need the hospitals and the hospitals need them; and secondly, educating their pupils, in which they must have assured assistance from a strong and essentially educational source.

At present the position of the nurses' school seems to be a false one. With all due respect to the hospitals we love and serve, they are tying us down, binding us and grinding out whaterer aspirations we may have to make the best and most of our schools. To accomplish anything we must be free,-not to stand alone, which seems beyond the limits of easy imagination, nor to desert the hospitals, which we would not leave if we could, but to have the positions of the schools readjusted so that they, recognized as of educational nature, complete in themselves and not an insignificant part of either, may unite with hospitals and with colleges, taking from both but in return giving back full measure in helpfulness. This tendency seems already to be showing itself. Whether it is the proper and a possible thing for the schools is for the future to decide. We may, however, take comfort in what has already been accomplished. We are ourselves becoming broader, less exclusive, and more concerned about the results of the whole as against our own little interests. Local superintendents' associations and state organizations, following the example of the national, have helped to bring us closer together; nursing journals are keeping us awake, and finally state registration will do much by compelling even unwilling effort for affiliation. The time is not being wasted; we are getting ourselves ready, and gradually working towards the object in view-affliation along all lines and with every interest which will enable schools for nurses to fulfill their obligations to the utmost and in the best, wisest and broadest manner. 